\title{
Effects of High-temperature Operating Conditions on The Through-plane Gas Permeability of Gas Diffusion Layers Used in PEFCs
}

Raja M. Aslam Raja Arif ${ }^{1}$

${ }^{1}$ School of Mechanical Engineering, College of Engineering, Universiti Teknologi MARA, Cawangan Johor, Kampus Pasir Gudang

"corresponding author: rajaaslam@uitm.edu.my

\section{ABSTRACT}

In order to simulate the effects of high-temperature operating conditions on the through-plane gas permeability of gas diffusion layers (GDLs) used in polymer electrolyte fuel cells, uncoated and coated GDLs were heated at various temperatures (i.e., 200, 500 and $800^{\circ} \mathrm{C}$ ). The results showed that the through-plane gas permeability of the uncoated GDLs generally increases after higher temperature treatment up to $7 \%$ from $2.34 \times 10^{-11} \mathrm{~m}^{2}$ to 2.51 $\mathrm{x} 10^{-11} \mathrm{~m}^{2}$ for SGL 10CA and up to $3 \%$ from $7.19 \times 10^{-12} \mathrm{~m}^{2}$ to $7.39 \times 10^{-12} \mathrm{~m}^{2}$ for Toray 060 . However, the coated GDL displayed a different trend: the through-plane gas permeability increased up to $2 \%$ from $4.87 \times 10^{-13}$ $\mathrm{m}^{2}$ to $4.96 \times 10^{-13} \mathrm{~m}^{2}$ with the increasing temperature treatment at 200 and $500{ }^{\circ} \mathrm{C}$, but then decreased $24 \%$ from $4.96 \times 10^{-13} \mathrm{~m}^{2}$ to $3.76 \times 10^{-13} \mathrm{~m}^{2}$ after heat treatment at 800 and $1000{ }^{\circ} \mathrm{C}$. With the assistance of SEM images, the above results are discussed.

Keywords: PEFCs, gas diffusion layer, gas permeability, high-temperature operation

\section{Nomenclature}

$\begin{array}{ll}K & \text { permeability } \\ L & \text { thickness } \\ \mu & \text { fluid viscosity } \\ \nu & \text { velocity } \\ Q & \text { volumetric flow rate } \\ D & \text { diameter }\end{array}$

\section{Abbreviations}

$\begin{array}{ll}\text { PEFC } & \text { polymer electrolyte fuel cell } \\ \text { GDL } & \text { gas diffusion layer } \\ \text { MPL } & \text { micro porous layer } \\ \text { PTFE } & \text { polytetrafluoroethylene }\end{array}$

\subsection{INTRODUCTION}

The polymer electrolyte fuel cell (PEFC) is the most-researched and promising type of fuel cell, due to some appealing features such as high efficiency and power density, low operation temperature, and quick start-up [12]. Furthermore, the PEFC is easily scalable and therefore some respective fuel cell systems have been demonstrated in a wide range of portable, automotive and stationary applications. To this end, there have been significant technical and economic improvements associated with the PEFC technology, namely increased performance, durability and reduced cost [3].

However, there are still some challenges that need to be resolved before realising the widespread commercialisation of the technology [4-6]. Water flooding, especially at the cathode, is one of the main challenges that PEFCs face and therefore it needs to be addressed [7-8]. High temperature PEFCs could be one of the solutions to the water flooding issue. However, investigations on how PEFC components perform under high temperature conditions are scarce. One of the main components in the PEFC, which is crucially important for water and thermal management, is the gas diffusion layer (GDL).

One of the vital functions of GDL is that it acts as a buffer layer through which gases and liquid water transport to/from the catalyst layer; thus, GDL must be sufficiently diffusive and permeable. One of the key characteristics of GDL is gas permeability, which is important to know in order to estimate the convective and capillary-driven flows of gases and liquid water, respectively. 
There have been a number of studies that investigated the effects of compression, PTFE loading, carbon loading and microporous layer (MPL) coating on gas permeability of GDLs; i.e., [9-11]. Gurau et al. [9] reported that the in- and through-plane gas permeability of MPL-coated GDLs increases with the increase of PTFE loading in MPL. Pharoah [10] showed that in-plane permeability plays a bigger role in transporting gases under ribs of the flow field plates than the through-plane permeability. Similar findings were presented by Gostick et al. [11]. In line with Gurau et al. [9], Ismail et al. [12] showed that the through-plane permeability of the GDL increases with the increase of PTFE loading in MPL. The through-plane permeability is shown to be significantly lower than the in-plane permeability [10-11]. Ihonen et al. [13] and Tamayol et al. [14] found that mechanical compression significantly reduces the through-plane gas permeability of GDL and may subsequently lead to water flooding.

To the best of the author's knowledge, there has been no investigation on how high operating temperatures $\left(<1000^{\circ} \mathrm{C}\right)$ affect the transport properties, including gas permeability of GDL. Such investigations are important to conduct as there has been a recent trend to operate PEFCs in the region of $100{ }^{\circ} \mathrm{C}$ to $200{ }^{\circ} \mathrm{C}$ in order to resolve water flooding [15-17]. Furthermore, increasing the operating temperature significantly (i.e. beyond $200{ }^{\circ} \mathrm{C}$ ) is expected to facilitate the use of non-precious catalyst in PEFCs, given that appropriate high operating-temperature membranes are used. It is noteworthy that some types of carbon fibres, subjected to special heat treatment, could feature high oxidative resistance at high temperatures of $750^{\circ} \mathrm{C}$ [18]. To this end and to shed some light on how the transport properties of GDL are affected after heat treatment at high temperatures $\left(<1000{ }^{\circ} \mathrm{C}\right)$, this study experimentally investigated the effect of such temperatures on gas permeability of GDL.

\subsection{EXPERIMENTAL INVESTIGATION}

\subsection{Experimental test setup and materials}

The experimental setup and procedures for the measurement of the through-plane gas permeability are described in this section. Fig. 1(a) shows the in-house experimental setup used to measure the through-plane gas permeability of the tested GDL samples.

The setup consists of upstream and downstream fixtures, and the GDL sample is positioned between these (Fig. 1(b)). Nitrogen gas flows at a fixed rate, using a flow controller (Teledyne Hastings HFC-202, UK), through the GDL sample. The resulting pressure drop is measured by a pressure sensor (Omega PX653, UK). The GDL samples are circular with a diameter of $25 \mathrm{~mm}$. However, after placing the sample between the two fixtures of the setup, the area exposed to the flow of nitrogen is only $20 \mathrm{~mm}$. As a result of clamping the sample between the two fixtures, some compression is imparted on the outer circumference of the GDL sample; thus, the through-plane permeability of the sample may be affected. However, the sensitivity of the through-plane permeability to the tightness of the fixing, whether the fixtures are loosely or tightly fixed, is insignificant, as investigated previously by Ismail et al. [19].

Eight different flow rates were tested for each GDL sample, and the pressure drop across the sample was then measured for each flow rate. Compared to the uncoated carbon substrates (e.g., SGL 10CA), MPL-coated GDL samples (e.g., SGL 10BC) must be tested with a lower range of flow rates as the relatively low porosity of the MPL causes the pressure sensor to reach its limit (i.e., $12.5 \mathrm{~Pa}$ ) at substantially lower flow rates. As shown in Section 2.3, the through-plane gas permeability of the GDL samples is estimated before and after being heated for one hour at the temperatures of 200,500 and $800{ }^{\circ} \mathrm{C}$. 

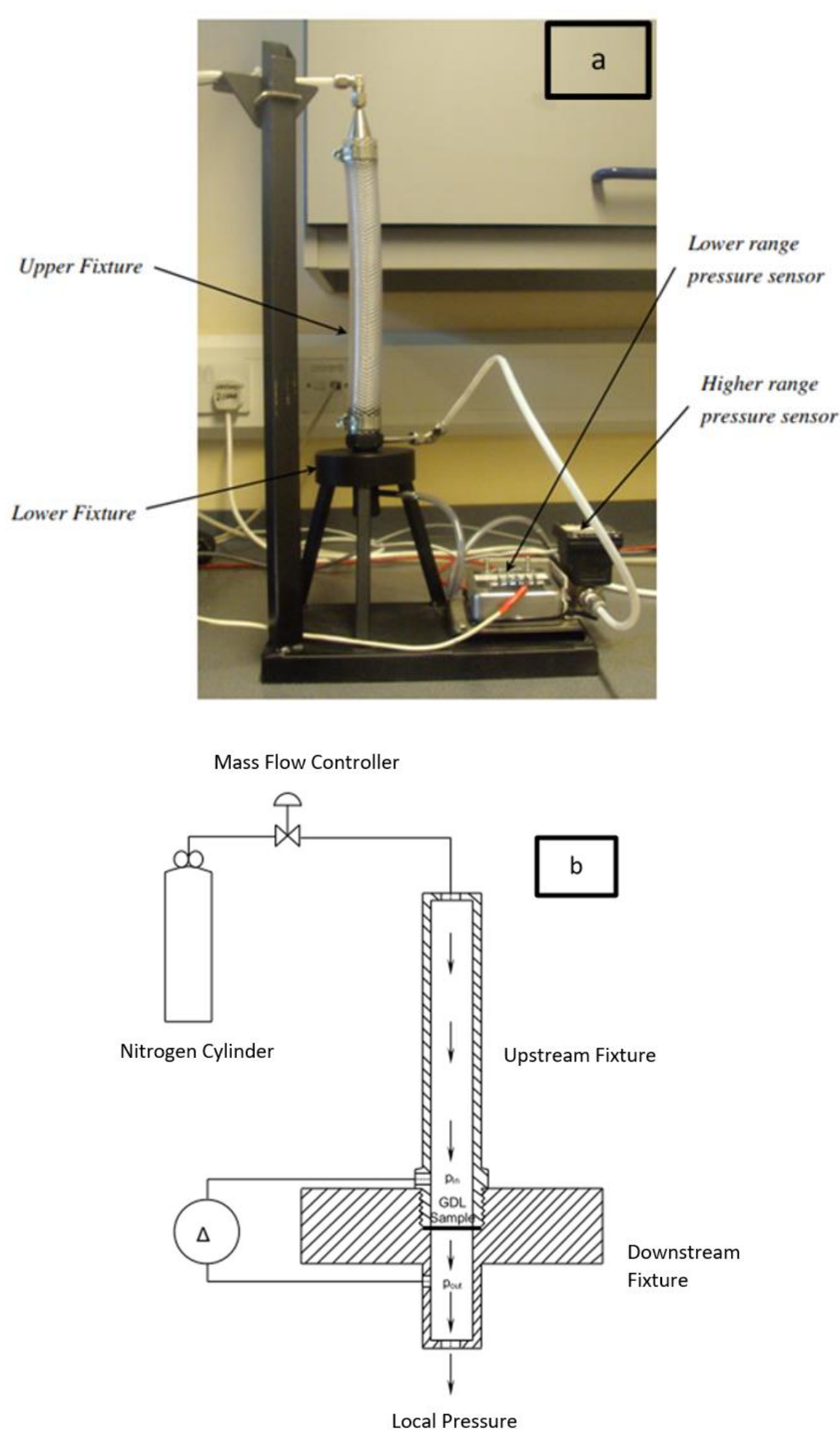

Figure 1. (a) A photograph of the in-house gas permeability setup; (b) A schematic diagram of the experimental setup (reprinted from Ref. [12] with permission of Elsevier)

Three GDL materials were tested; two uncoated carbon substrates (namely, SGL 10CA and Toray 60), and one MPL-coated GDL (SGL 10BC). Table 1 lists the GDL materials along with their porosity and mean pore diameter. Note that the initial intension used was SGL 10BA rather than SGL 10CA in order to have a better consistency across the investigated materials as the carbon substrate of the coated GDL material SGL 10BC is SGL 10BA. However, SGL 10BA GDL was not available in our laboratory and we were not able to purchase new sheets of this material as the respective manufacturer (i.e., SGL Carbon Group) no longer produces SGL 10 based GDLs. Fortunately, SGL 10CA, which is structure-wise very similar to SGL 10BA, was available and therefore 
used in this investigation. Namely, SGL 10CA has more or less the same thickness, porosity and mean pore diameter as those of SGL 10BA. The only difference is that the PTFE loading of SGL 10CA (10 wt. \%) is slightly higher than that of SGL 10BA (5 wt. \%) [18]; (refer Table 1).

Table 1: Key geometrical properties of the investigated GDL materials

\begin{tabular}{cccccc}
\hline $\begin{array}{c}\text { GDL } \\
\text { Material }\end{array}$ & $\begin{array}{c}\text { Thickness } \\
(\boldsymbol{\mu m})\end{array}$ & Porosity (-) & $\begin{array}{c}\text { Mean pore } \\
\text { dimeter }(\boldsymbol{\mu m})\end{array}$ & $\begin{array}{c}\text { PTFE Loading } \\
(\mathbf{w t .} \%)\end{array}$ & $\begin{array}{c}\text { MPL PTFE } \\
\text { Loading (wt. \%) }\end{array}$ \\
\hline SGL 10CA & $400[19]$ & $0.88[19]$ & $52[20]$ & $10[19]$ & N/A \\
Toray 060 & $190[21]$ & $0.63[21]$ & $2.6[21]$ & $5[22]$ & N/A \\
SGL 10BC & $420[21]$ & $0.35[21]$ & $3[21]$ & $5[12]$ & $23[12]$ \\
\hline
\end{tabular}

\subsection{Data analysis}

The main cause for pressure drop across the sample with sufficiently small gas velocity is viscous resistance to the fluid flow, as described by Darcy's Law [11]. Darcy's law is an equation that linearly relates the flow rate across the porous medium to the pressure drop resulting from that flow rate. The proportionality constant includes the gas permeability, $K$, as follows:

$$
\begin{aligned}
& \frac{\Delta P}{L}=\frac{\mu}{K} v \\
& v=\frac{Q}{\pi \frac{D^{2}}{4}}
\end{aligned}
$$

where $\Delta \mathrm{P}$ is the pressure drop across the sample, $L$ is the thickness of the sample, $\mu$ is the dynamic fluid viscosity of the nitrogen gas at the test temperature $\left(\sim 20^{\circ} \mathrm{C}\right), v$ is the velocity of the flowing gas, $Q$ is the volumetric flow rate and $D$ is the diameter of the sample exposed to the flow. It should be noted that, at relatively high velocities, the inertial resistance becomes more important and may have to be taken into account when estimating the gas permeability of the porous media. The equation that considers viscous and inertial losses is known as Forchheimer equation. The relationship between pressure gradient $(\Delta P / L)$ and velocity $(v)$ is found to be linear for all the investigated cases; therefore, Darcy's law is used to estimate gas permeability of the GDL samples by equating the slope of the curve to $\mu / K$ [23].

The number of samples for each GDL material was six and the reported gas permeability was the average value of all the permeability values of the six samples with a 95\% confidence interval around that average value.

\subsection{Heating setup}

Tube furnace (VCTF, Vecstar Ltd, UK) was used to heat the GDL samples. The maximum temperature available for the furnace was $1200^{\circ} \mathrm{C}$. All the six samples for each GDL material were heated for one hour at 200, 500 and $800{ }^{\circ} \mathrm{C}$ (or $1000{ }^{\circ} \mathrm{C}$ in one case). Nitrogen gas was flowed through the tube of the furnace to avoid oxidation of the samples, and the gas permeability was measured before and after heat treatment.

To help explain the results of gas permeability before and after the heating of the GDLs, they were imaged using a scanning electron microscope (SEM, JEOL JSM-601LA).

\subsection{RESULTS AND DISCUSSION}

Table 2 lists and Fig. 2 plots the average gas permeability for all the tested GDL materials after the heating at each temperature. Noteably, the mean values lie within the margin of errors The results showed that the throughplane gas permeability of the tested carbon substrates materials (i.e. uncoated GDLs) generally increases as the temperature increases from room temperature to $800{ }^{\circ} \mathrm{C}$. However, this does not appear to be the case for the MPL-coated GDL, where the permeability increases from room temperature to $500{ }^{\circ} \mathrm{C}$, and decreases at $800{ }^{\circ} \mathrm{C}$. Notably, the permeability of all the GDL materials slightly increases after being heated at $200{ }^{\circ} \mathrm{C}$. This is most likely due to insignificant morphological changes of the GDL materials at this temperature, which is lower than the melting point of PTFE $\left(\sim 325^{\circ} \mathrm{C}\right)$ [24]. In addition, it can be seen from Table 2 and Fig. 2 that 10BC GDL 
showed the smallest permeability value. This is clearly due to the presence of MPL which has a lower porosity than GDL, resulting in less overall porosity, less mean pore diameter, higher thickness (as shown in Table 1) and ultimately gas permeability of at least two orders of magnitude lower than that of the corresponding carbon substrate [12]. Furthermore, the permeability values of Toray GDL are one order of magnitude lower than those of SGL 10CA. This is evidently due to the significantly smaller porosity and mean pore diameter featured by Toray 060 GDL compared to SGL 10CA (refer Table 1). This is corroborated with the values of bulk density reported/calculated for the above two carbon substrates; $0.43 \mathrm{~g} / \mathrm{cm}^{3}$ for Toray 060 [21] and $0.21 \mathrm{~g} / \mathrm{cm}^{3}$ for SGL 10CA [19].

Table 2: Average through-plane gas permeability of GDL materials at room temperature and after heating at various temperatures

\section{Through-plane gas permeability $\left(\mathrm{m}^{2}\right)$}

GDL

$\begin{array}{llll}\text { Material } & \text { Room temperature } & 200 & \circ \\ \end{array}$

\begin{tabular}{lllll}
\hline SGL 10CA & $2.34( \pm 0.15) \times 10^{-11}$ & $2.35( \pm 0.14) \times 10^{-11}$ & $2.41( \pm 0.15) \times 10^{-11}$ & $2.51( \pm 0.16) \times 10^{-11}$ \\
Toray 060 & $7.19( \pm 0.13) \times 10^{-12}$ & $7.18( \pm 0.32) \times 10^{-12}$ & $7.37( \pm 0.50) \times 10^{-12}$ & $7.39( \pm 0.25) \times 10^{-12}$ \\
SGL 10BC & $4.87( \pm 0.35) \times 10^{-13}$ & $4.86( \pm 0.42) \times 10^{-13}$ & $4.96( \pm 0.30) \times 10^{-13}$ & $3.76( \pm 0.50) \times 10^{-13}$
\end{tabular}

*Note that the error numbers represent $95 \%$ confidence intervals around the mean values.

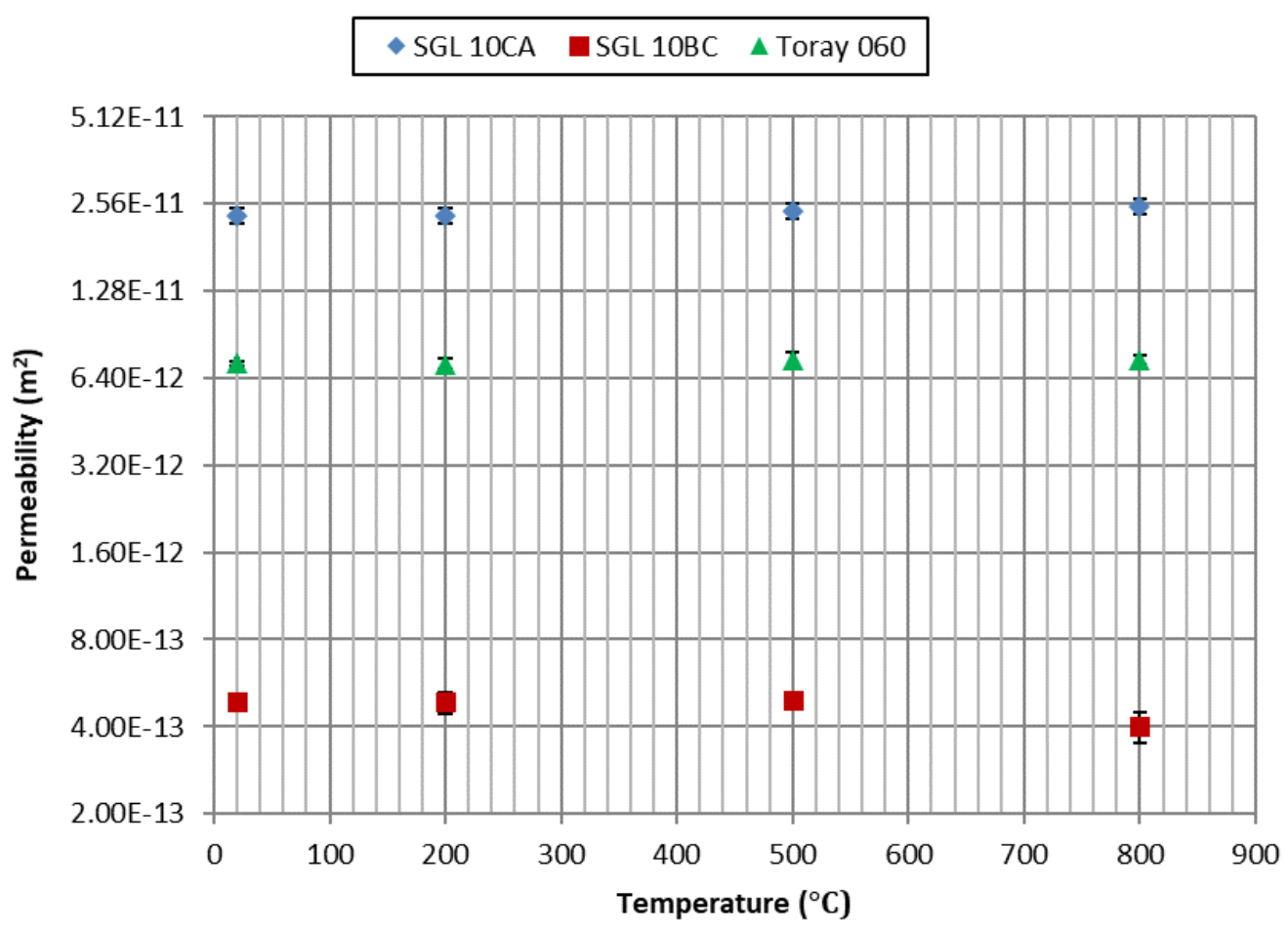

Figure 2. Through-plane gas permeability of all GDL samples investigated after heating at different temperatures. Note that a base-2 log scale is used for the Y-axis

Figs. 3, 4 and 5 show SEM images of SGL 10CA, Toray 060 and SGL 10BC GDLs, respectively, at room temperature and after heat treatment at 2 different magnifications of 50x and 300x. It is seen from Fig. 3 (a-d) that the amount of PTFE webbing between the carbon fibres of SGL 10CA GDL is almost unchanged between room temperature and $200{ }^{\circ} \mathrm{C}$, but the morphology changes slightly at 500 and $800{ }^{\circ} \mathrm{C}$. This is confirmed in the higher magnification of SEM images, i.e., Fig. 3 (e-h), which show that there is significantly less of the relatively bright and smooth material, i.e., the PTFE webbing [25], connecting the fibres at 500 and $800{ }^{\circ} \mathrm{C}$ than at lower 
temperatures; the regions encircled by the dotted red lines represent the bright and smooth PTFE webbing. The melting point of PTFE is about $325^{\circ} \mathrm{C}$, so little change in permeability is expected at $200{ }^{\circ} \mathrm{C}$. The change in morphology after higher temperature heat treatment may be explained by the melting and decomposition/carbonization of the PTFE material at higher temperature. This also explains the changes in permeability. The loss of PTFE material with temperature for Toray 060 is not as clear as that for SGL 10CA (refer Fig. 4). This is probably due to the fact that Toray 060 is treated with less PTFE (5 wt. \%) than SGL 10CA (10 wt. \%). Also, it appears that the binder used for Toray 060 is, unlike that used for SGL 10CA, rather smooth and thus making it difficult to distinguish between the binder and PTFE hydrophobic agent used for Toray 060 . Overall, the apparent and slight increase in the gas permeability of Toray 060 with temperature is mostly attributed to the loss of PTFE material which starts to decompose/melt after around $325^{\circ} \mathrm{C}$. The loss of hydrophobic agent, i.e., PTFE, is something undesirable for low-temperature PEFCs $\left(<100^{\circ} \mathrm{C}\right)$ where the management of liquid water is crucially important. However, intermediate- and high-temperature operating PEFC $\left(>100^{\circ} \mathrm{C}\right)$ do not need the GDL materials to be PTFE-treated as water is typically present in vapour form. This should translate into reduced manufacturing cost when designing and using GDLs for PEFCs operating at relatively high temperatures (> $\left.100^{\circ} \mathrm{C}\right)$.

On the other hand, Fig. 5(a-d) shows that the number and size of the cracks in the MPL of SGL 10BC GDL material increase with the increase of temperature. This reasonably justifies the increase in gas permeability of SGL 10BC GDL material when the temperature increases from room temperature to 200 and $500{ }^{\circ} \mathrm{C}$. However, the decrease in gas permeability of SGL $10 \mathrm{BC}$ from 500 to $800{ }^{\circ} \mathrm{C}$ is difficult to explain from the SEM images. To confirm the above trend, fresh SGL 10BC samples were subjected to heating courses at all the above set temperatures (i.e., 200,500 and $800^{\circ} \mathrm{C}$ ), plus $1000^{\circ} \mathrm{C}$. The resulting permeability after heating to $1000^{\circ} \mathrm{C}$ decreased by around 4\% which confirming the trend. Furthermore, SEM images taken on SGL 10BC GDL after heating at $1000^{\circ} \mathrm{C}$ (Fig. 5(e)) showed that beyond $500^{\circ} \mathrm{C}$, a "spreading effect" where the cracks and gaps are generally closed up may occur. Overall, a full explanation of these phenomena requires employment of more sophisticated 3-dimensional structure-related tests, such as X-ray tomography. 

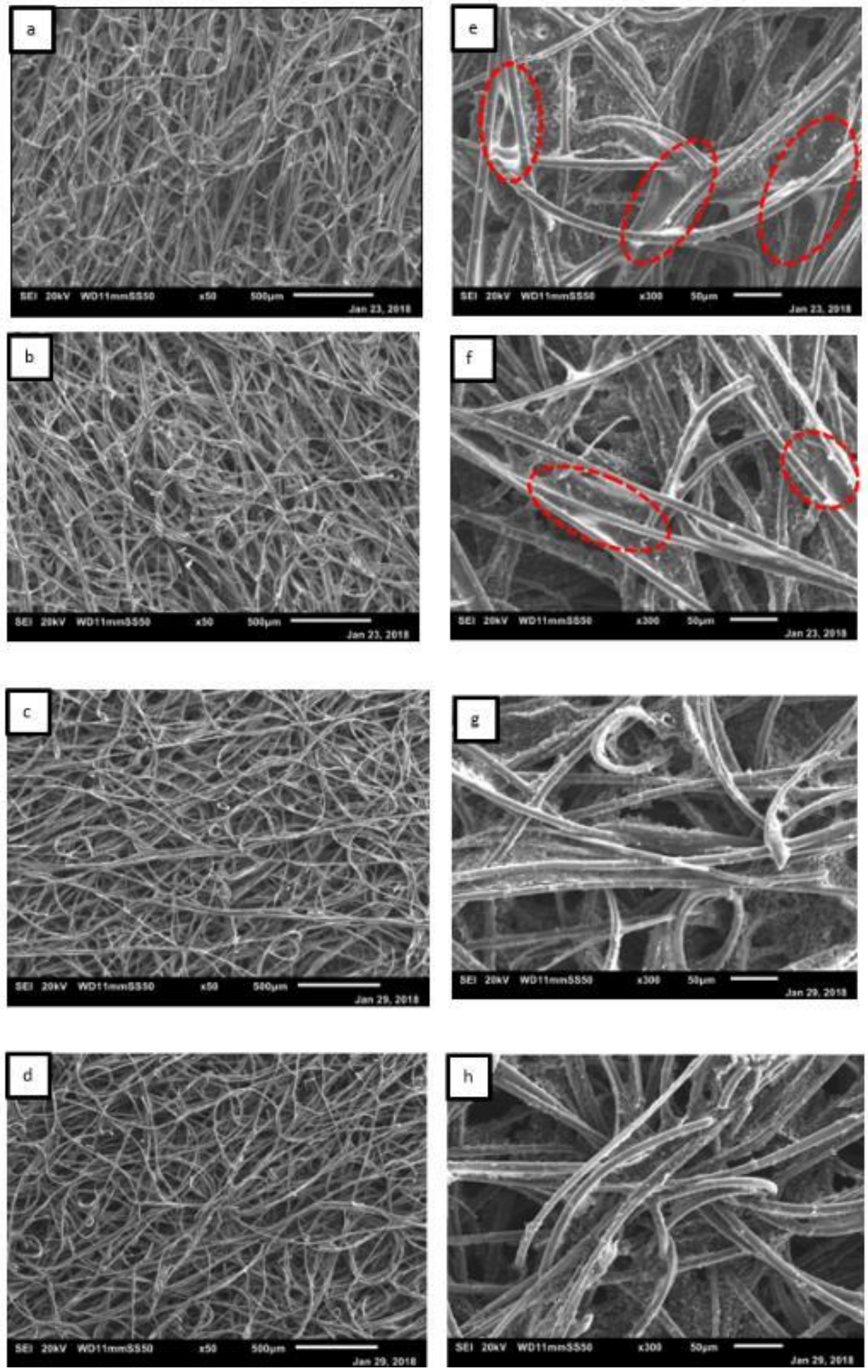

Figure 3. SEM images of SGL 10CA at 50x magnification at; (a) room temperature, and after heating; (b) $200{ }^{\circ} \mathrm{C}$; (c) $500{ }^{\circ} \mathrm{C}$; and (d) $800{ }^{\circ} \mathrm{C} .300 \mathrm{x}$ magnification at; (e) room temperature, and after heating; (f) $200^{\circ} \mathrm{C}$; (g) $500{ }^{\circ} \mathrm{C}$; and (h) $800{ }^{\circ} \mathrm{C}$ 

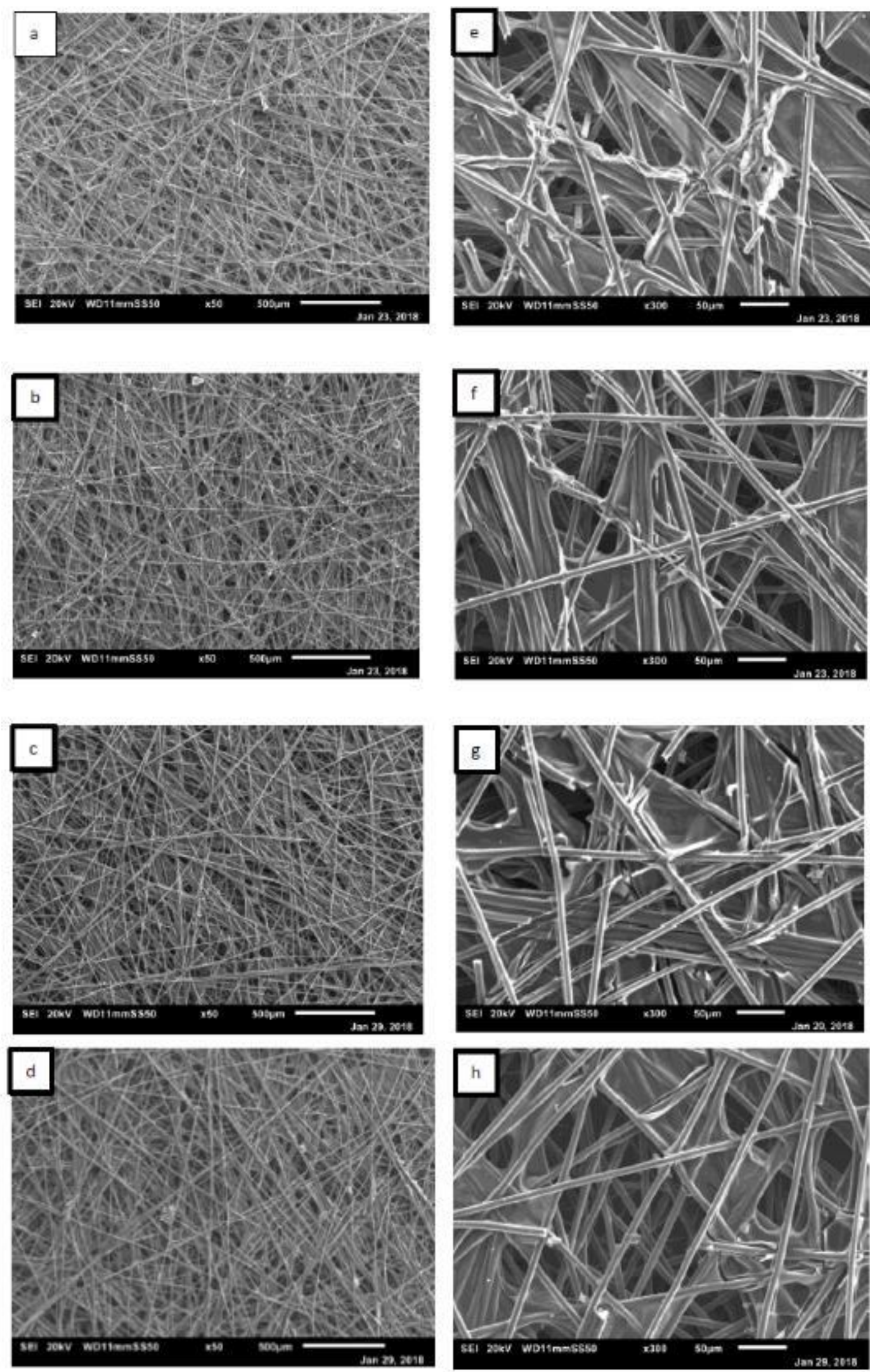

Figure 4. SEM images of Toray 60 at 50x magnification at; (a) room temperature, and after heating; (b) 200 ${ }^{\circ} \mathrm{C}$; (c) $500{ }^{\circ} \mathrm{C}$; and (d) $800{ }^{\circ} \mathrm{C}$. 300x magnification at; (e) room temperature, and after heating; (f) $200{ }^{\circ} \mathrm{C}$; (g) $500{ }^{\circ} \mathrm{C}$; and (h) $800{ }^{\circ} \mathrm{C}$ 

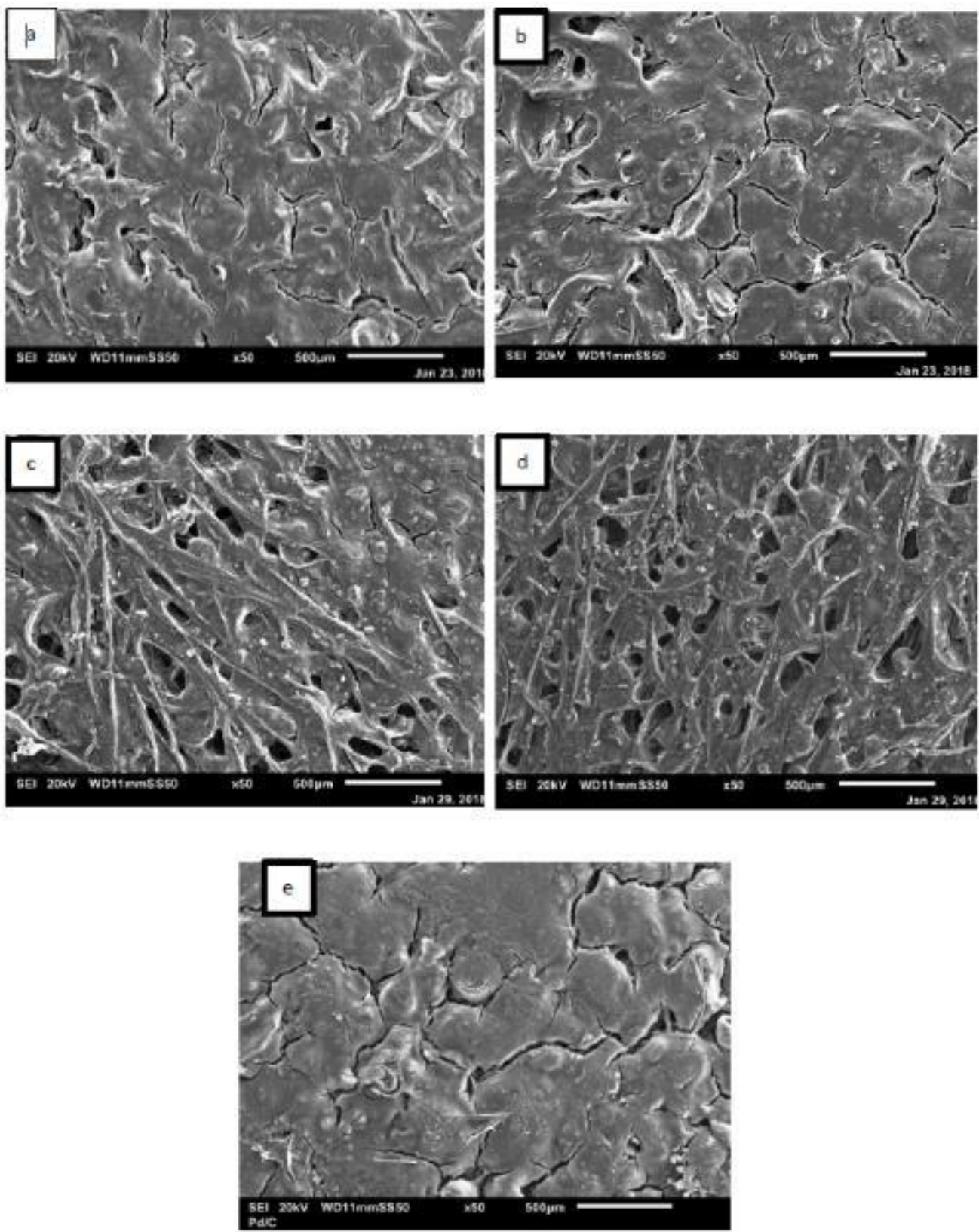

Figure 5. SEM images of SGL $10 \mathrm{BC}$ at 50x magnification at; (a) room temperature, and after heating; (b) $200{ }^{\circ} \mathrm{C}$; (c) $500{ }^{\circ} \mathrm{C}$; (d) $800{ }^{\circ} \mathrm{C}$; and (e) $1000{ }^{\circ} \mathrm{C}$

\subsection{CONCLUSION}

In this investigation, uncoated and coated GDLs were subjected to heating at temperatures up to $1000{ }^{\circ} \mathrm{C}$ in order to simulate the effects of high-temperature operating conditions on the gas permeability of GDLs used in PEFCs. The followings are the main findings:

- The through-plane gas permeability of the uncoated GDLs, i.e., SGL 10CA and Toray 060, increases as the heating temperature is increased up to 500 and $800{ }^{\circ} \mathrm{C}$. This is attributed to the fact that the PTFE material melts and then decomposes above $325^{\circ} \mathrm{C}$, significantly altering the morphology.

- The through-plane gas permeability of the MPL-coated GDL, i.e., SGL 10BC, increases as the heating temperature is increased from room temperature to 200 and $500{ }^{\circ} \mathrm{C}$, but decreases after heating to 800 and $1000^{\circ} \mathrm{C}$. With the assistance of SEM images, this appears to be due to a "spreading effect", where the cracks and gaps are partially sealed due to changes in morphology of the MPL. 
From these findings, the permeability of the GDLs used in PEFCs under higher temperature is measured which gives an insight of the high temperature PEM fuel cell. Further investigation is required to achieve better understanding on the high temperature PEM fuel cell operation in order to resolve the water flooding issue.

\section{ACKNOWLEDGEMENT}

The author gratefully acknowledges the financial support provided by the Malaysia Government through the MARA Education Fund. The content of this manuscript has been partly published in Chapter 6 as part of the thesis of R.M. Aslam [26].

\section{REFERENCES}

[1] C. Dyer, "Fuel cells for portable applications," Fuel Cells Bull., no. 42, pp. 9-10, 2002.

[2] E. Carcadea, H. Ene, D. B. Ingham, R. Lazar, L. Ma, M. Pourkashanian, and I. Stefanescu, "A computational fluid dynamics analysis of a PEM fuel cell system for power generation," Int. J. Numer. Methods Heat Fluid Flow, vol. 17, no. 3, pp. 302-312, 2007.

[3] J. Stumper and C. Stone, "Recent advances in fuel cell technology at Ballard," J. Power Sources, vol. 176, no. 2, pp. 468-476, Feb. 2008.

[4] K. Sopian and W. R. Wan Daud, "Challenges and future developments in proton exchange membrane fuel cells,” Renew. Energy, vol. 31, no. 5, pp. 719-727, Apr. 2006.

[5] M.S. Ismail. L. Ma, K.J. Hughes, D.B. Ingham and M. Pourkashanian, "Effect of PTFE loading of gas diffusion layers on the performance of proton exchange membrane fuel cells running at high-efficiency operating conditions," Int. J. ENERGY Res., vol. 37, no. 13, pp. 1592-1599, 2013.

[6] A. El-kharouf, A. Chandan, M. Hattenberger, and B. G. Pollet, "Proton exchange membrane fuel cell degradation and testing: review," J. Energy Inst., vol. 85, no. 4, pp. 188-200, 2012.

[7] K. Jiao and X. Li, "Water transport in polymer electrolyte membrane fuel cells," Prog. Energy Combust. Sci., vol. 37, no. 3, pp. 221-291, Jun. 2011.

[8] H. Li, Y. Tang, Z. Wang, Z. Shi, S. Wu, D. Song, J. Zhang, K. Fatih, J. Zhang, H. Wang, Z. Liu, R. Abouatallah, and A. Mazza, "A review of water flooding issues in the proton exchange membrane fuel cell,” J. Power Sources, vol. 178, no. 1, pp. 103-117, Mar. 2008.

[9] V. Gurau, M. J. Bluemle, E. S. De Castro, Y. M. Tsou, T. A. Zawodzinski, and J. A. Mann, "Characterization of transport properties in gas diffusion layers for proton exchange membrane fuel cells. 2. Absolute permeability," J. Power Sources, vol. 165, no. 2, pp. 793-802, 2007.

[10] J. G. Pharoah, "On the permeability of gas diffusion media used in PEM fuel cells," J. Power Sources, vol. 144, no. 1, pp. 77-82, 2005.

[11] J. T. Gostick, M. W. Fowler, M. D. Pritzker, M. A. Ioannidis, and L. M. Behra, "In-plane and throughplane gas permeability of carbon fiber electrode backing layers," J. Power Sources, vol. 162, no. 1, pp. 228-238, 2006.

[12] M. S. Ismail, D. Borman, T. Damjanovic, D. B. Ingham, and M. Pourkashanian, "On the through-plane permeability of microporous layer-coated gas diffusion layers used in proton exchange membrane fuel cells,” Int. J. Hydrogen Energy, vol. 36, no. 16, pp. 10392-10402, 2011.

[13] J. Ihonen, M. Mikkola, and G. Lindbergh, "Flooding of Gas Diffusion Backing in PEFCs," J. Electrochem. Soc., vol. 151, no. 8, p. A1152, 2004.

[14] A. Tamayol, F. McGregor, and M. Bahrami, "Single phase through-plane permeability of carbon paper gas diffusion layers," J. Power Sources, vol. 204, pp. 94-99, 2012.

[15] S. J. Andreasen, J. R. Vang, and S. K. Kær, "High temperature PEM fuel cell performance characterisation with $\mathrm{CO}$ and CO2 using electrochemical impedance spectroscopy," Int. J. Hydrogen Energy, vol. 36, no. 16, pp. 9815-9830, 2011.

[16] J. Lobato, P. Cañizares, M. A. Rodrigo, F. J. Pinar, E. Mena, and D. Úbeda, "Three-dimensional model of a $50 \mathrm{~cm} 2$ high temperature PEM fuel cell. Study of the flow channel geometry influence," Int. J. Hydrogen Energy, vol. 35, no. 11, pp. 5510-5520, 2010.

[17] A. Chandan, M. Hattenberger, A. El-Kharouf, S. Du, A. Dhir, V. Self, B. G. Pollet, A. Ingram, and W. Bujalski, "High temperature (HT) polymer electrolyte membrane fuel cells (PEMFC)-A review," J. Power Sources, vol. 231, pp. 264-278, 2013.

[18] G. Smith, "Oxidation resistance of pyrolytically grown carbon fibers," Carbon, vol. 22, issue 6, pp. 477479, 1984.

[19] M. S. Ismail, T. Damjanovic, K. Hughes, D. B. Ingham, L. Ma, M. Pourkashanian, and M. Rosli, “ThroughPlane Permeability for Untreated and PTFE-Treated Gas Diffusion Layers in Proton Exchange Membrane Fuel Cells," J. Fuel Cell Sci. Technol., vol. 7, no. 5, p. 051016, 2010.

[20] S. Park, and B.N Popov, "Effect of a GDL based on carbon paper or carbon cloth on PEM fuel cell performance" Fuel, vol. 90, no. 1, pp. 436-440, 2011. 
[21] A. El-kharouf, T.J. Mason, DJ.L. Brett, B.G Pollet, "Ex-situ characterisation of gas diffusion layers for proton exchange membrane fuel cells", Journal of Power Sources, 218, pp. 393-404, 2012.

[22] Toray Carbon Paper 060, Wet Proofed, Fuel Cell Store, July 2021. [Online]. Available: https://www.fuelcellstore.com/fuel-cell-components/gas-diffusion-layers/carbon-paper/toray-carbonpaper/toray-carbon-paper-060.

[23] D. Shou, Y. Tang, L. Ye, J. Fan, and F. Ding, "Effective permeability of gas diffusion layer in proton exchange membrane fuel cells," Int. J. Hydrogen Energy, vol. 38, no. 25, pp. 10519-10526, 2013.

[24] A. Oshima, Y. Tabata, H. Kudoh, and T. Seguchi, "Radiation induced crosslinking of polytetrafluoroethylene," Radiat. Phys. Chem., vol. 45, no. 2, pp. 269-273, 1995.

[25] M. S. Ismail, T. Damjanovic, D. B. Ingham, M. Pourkashanian, and A. Westwood, "Effect of polytetrafluoroethylene-treatment and microporous layer-coating on the electrical conductivity of gas diffusion layers used in proton exchange membrane fuel cells," J. Power Sources, vol. 195, no. 9, pp. 2700-2708, 2010.

[26] R. M. A. Raja Arif, "Water and Thermal Management of PEM Fuel Cells," Ph.D. dissertation, Department of Mechanical Engineering, Faculty of Engineering, University of Sheffield, 2018. [Online]. Available: http://etheses.whiterose.ac.uk/21899/1/Phd\%20Thesis\%20Raja.pdf 